\title{
Other Procedure Type for New Tumor
}

\section{Event}

National Cancer Institute

\section{Source}

National Cancer Institute. Other Procedure Type for New Tumor Event. NCI Thesaurus.

Code C158757.

A directive to specify the procedure which is other than is listed on the form. 